\title{
MODEL KELAS PENYELENGGARA PENDIDIKAN INKLUSIF DI SDN MEDAN
}

\author{
Dahniar Harahap \\ Nina Hastina \\ Program Studi Pendidikan Guru Sekolah Dasar \\ Universitas Nahdlatul Ulama Sumatera Utara \\ Email: niar.harahap20@gmail.com; ninahastina4@gmail.com
}

Artikel diterima: 1 November 2017; disetujui: 31 Mei 2019

\begin{abstract}
This study aims to reveal the existence and type of students with special needs in elementary school (SD) providers of inclusive education in the city of Medan. The research subjects included 4 elementary schools in Marelan Medan. Collecting data from the results of observations, interviews and documentation. The results of the analysis show that 2 schools place students in regular classes with clusters, 1 school with regular classes with pull outs and 1 full special class school. Types of students who have special needs consist of $52 \%$ mild mental retardation, $30 \%$ moderate mental retardation, $17 \%$ learning difficulties and $1 \%$ deaf. It is recommended to place students in each regular class and accept students in placements in public schools.
\end{abstract}

Keywords: Inclusive Education, Students with Special Needs, Elementary Schools

\begin{abstract}
Abstrak: Penelitian ini bertujuan untuk mengungkapkan keberadaan dan jenis siswa berkebutuhan khusus di Sekolah Dasar (SD) penyelenggara pendidikan inklusif di kota Medan. Subjek penelitian meliputi 4 SDN di Medan Marelan. Pengumpulan data dari hasil observasi, wawancara dan dokumentasi. Hasil analisis menunjukkan 2 sekolah menempatkan siswa pada kelas reguler dengan cluster, 1 sekolah dengan kelas reguler dengan pull out dan 1 sekolah kelas khusus penuh. Jenis siswa yang memiliki kebutuhan khusus terdiri dari $52 \%$ tunagrahita ringan, $30 \%$ tunagrahita sedang, $17 \%$ kesulitan belajar dan 1\% tunarungu. Direkomendasikan untuk menempatkan siswa di setiap kelas reguler dan menerima siswa dalam penempatan di sekolah umum.
\end{abstract}

Kata Kunci: Pendidikan Inklusif, Siswa Berkebutuhan Khusus, Sekolah Dasar

Pendidikan inklusif menjadi sebuah upaya radikal dalam memandang sistem pendidikan dengan asumsi dasar bahwa semua orang berhak memperoleh pendidikan. Pendidikan inklusif merupakan bentuk penyelenggaraan pendidikan yang menyatukan siswa-siswa berkebutuhan khusus dengan siswasiswa normal pada umumnya untuk belajar (Devy, 2017). Pendidikan inklusif menyediakan sebuah jalur untuk memberikan kesempatan yang sama untuk siswa berkebutuhan khusus dan memastikan kesempatan siswa untuk memperoleh pendidikan dengan kurikulum yang sesuai, strategi pembelajaran, dan pola hubungan dalam komunitas (Priyadarshini \& Thangarajathi, 2016). Penyelenggaraan pendidikan inklusif secara umum mendukung model sosial dan dimaksudkan untuk mempromosikan ketidakinklusifan di semua aspek kehidupan (Fernández, 2017). Hal ini memberikan kesempatan untuk siswa yang memiliki kebutuhan khusus dan tidak mampu dari segi materil dan lokasi 
yang jauh untuk mendapatkan pendidikan di sekolah khusus misalnya Sekolah Luar Biasa (SLB).

Secara regulasi, pendidikan inklusif tertuang dalam beberapa dokumen pemerintah. Pertama yaitu pendidikan inklusif tertuang dalam Undang Undang Republik Indonesia Nomor 20 Tahun 2003 tentang Sistem Pendidikan Nasional dalam penyediaan pendidikan bagi siswa berkebutuhan khusus. Kedua, yaitu Permendiknas Nomor 70 Tahun 2009 tentang pendidikan inklusif yang menjabarkan pendidikan inklusif sebagai sebuah sistem penyelenggaraan pendidikan yang memberikan kesempatan kepada semua siswa yang memiliki kelainan dan memiliki potensi kecerdasan dan/ atau bakat istimewa untuk mengikuti pendidikan atau pembelajaran dalam lingkungan pendidikan secara bersama-sama dengan siswa pada umumnya. Adapun regulasi mendasar yaitu dituangkannya hak dasar pendidikan bagi siswa berkebutuhan khusus dalam Pasal 31 Ayat (1) UUD 1945 yang berbunyi "setiap warga negara berhak mendapat pendidikan". Kesemua regulasi tersebut menaungi dan melandasi pendidikan inklusif yang diterapkan di Indonesia.

Untuk mencapai tujuan pendidikan dimana inklusi menjadi praktek penyelenggaraan yang mendidik dibutuhkan pemahaman terkait pembelajaran di sekolah. Guru dalam pembelajaran perlu memahami fungsi sosial dari pendidikan inklusif dengan memngindikasikan bahwa siswa normal belajar untuk menerima dan memahami siswa lain yang berbeda, yang mana dapat diintegrasikan dalam pembelajaran (Hwang dan Evans, 2011). Terlebih lagi studi menunjukkan bahwa kurang dari 25\% guru memiliki pengetahuan terkait pembelajaran tentang kelas inkulisf dengan siswa berkebutuhan khusus sehingga ada ketidakmampuan untuk mengakomodasi kesuksesan siswa (Abbas \& Naz, 2016). Oleh sebab itu, perlu diketahui model-model pembelajaran dalam pendidikan inklusif sebagai bagian dari pencapain tujuan pembelajaran secara umum.

Terkait dengan penyelenggaraan pembelajaran dalam pendidikan inklusif diperlukan pula modelmodel pembelajaran yang sesuai. Ashman (dalam Elisa; 2013) menglasifikasikan model pendidikan siswa berkebutuhan khusus di sekolah inklusif yaitu (1) kelas reguler (inklusif penuh), (2) kelas reguler dengan cluster, (3) kelas reguler dengan pull out, (4) kelas reguler dengan cluster dan pull out, (4) kelas khusus dengan berbagai pengintegrasian, dan (5) kelas khusus penuh. Dalam kelas reguler kegiatan pembelajaran dengan kurikulum yang sama dilakukan baik oleh siswa berkebutuhan khusus ataupaun tidak di dalam kelas yang sama. Dalam sistem reguler berkluster, siswa yang berkebutuhan khusus dikelompokkan tersendiri dimana model ini cukup berbeda dengan sistem pull out dimana siswa dalam waktu tertentu ditarik dari kelas reguler untuk belajar dengan mendapatkan bimbingan khusus dari guru (Mardini, 2016). Berbeda lagi dengan kelas reguler dengan cluster dan pull out yang memberikan kesempatan bagi siswa berkebutuhan khusus untuk belajar bersama siswa non berkebutuhan khusus di kelas reguler dalam kelompok khusus, dan dalam waktu-waktu tertentu ditarik dari kelas reguler ke ruang lain untuk belajar dengan guru pembimbing khusus. Selanjutnya, yaitu kelas khusus dengan berbagai pengintegrasian siswa berkebutuhan khusus belajar di dalam kelas khusus pada sekolah reguler namun dalam bidang-bidang tertentu dapat belajar bersama siswa non berkebutuhan khusus di kelas reguler. Adapun siswa kelas khusus penuh yaitu siswa berkebutuhan khusus belajar di dalam kelas khusus pada sekolah reguler.

Pada umumnya sekolah khusus Siswa Berkebutuhan Khusus (ABK) berada di ibukota provinsi atau ibukota kabupaten/kota yang menyebabkan siswa ABK yang tinggal dipedasaan, banyak yang tidak mendapatkan hak pendidikan karena keterbatasan ekonomi dan lokasi sekolah yang jauh. Oleh karena itulah pendidikan inklusif yang diselenggarakan pemerintah sangat membantu siswa berkebutuhan khusus tetap dapat menikmati hak untuk pendidikan karena sekolah umum dapat menerima mereka sama seperti siswa pada umumnya.

Oleh sebab itu, pada tahun 2015 Sumatera Utara mendeklarasikan diri sebagai provinsi pendidikan inklusif di Indonesia dengan kurang lebih 633 sekolah menyatakan siap untuk menyelenggarakan pendidikan inklusif. Kota Medan adalah ibu kota dari Provinsi Sumatera Utara yang diberikan kesempatan oleh pemerintah untuk menyelenggarakan pendidikan inklusif yang diawali dengan kegiatan penyusunan pedoman penyelenggaraan sekolah inklusif, sosialisasi kepada berbagai komponen terkait dan secara simultan dilakukan perintisan sekolah inklusif di berbagai kecamatan di Kota Medan. Sekolah yang tersebar di kabupaten atau kota di Sumatera Utara menerima siswa-siswa ABK untuk bersekolah di sekolah reguler. Badan Pusat Statistik mencatatkan terdapat sebanyak 285.982 siswa berkebutuhan khusus, dari 2.859.824 total siswa usia sekolah di 
Sumatera Utara. Angka ini merujuk asumsi PBB yang menyebut setidaknya 10 persen dari jumlah siswa usia sekolah (5-14 tahun) adalah penyandang kebutuhan khusus. Dan dari jumlah tersebut hanya 0.00018 persen yang dapat mengakses pendidikan ke Sekolah Dasar (SD) dan 0,00012 persen ke SMP (Atika, 2018).

Pendidikan inklusif diharapkan dapat menjadi salah upaya untuk meningkatkan partisipasi siswa bersekolah (berkebutuhan khusus) dan dalam waktu bersamaan dapat meningkatkan pendidikan inklusif diharapkan mutu pendidikan Prastiono (2013:119). Pendidikan inklusif secara tradisional dikaitkan dengan siswa berkebutuhan khusus. Lebih lanjut, Ilahi (2013:183) menjelaskan bahwa siswa merupakan komponen penting dalam pelaksanaan pendidikan inklusif.

Masih banyak siswa-siswa berkebutuhan khusus yang belum memperoleh pendidikan. Kondisi ini disebabkan adanya berbagai hambatan termasuk didalamnya kondisi sosial dari masyarakat (Prastiono, 2013). Simbol yang digunakan oleh sekolah untuk mengklasifikasikan jenis kebutuhan khusus siswa disajikan pada Tabel 1 berikut. Terkait dengan klasifikasi tersebut, studi pendahuluan yang dilakukan oleh Khan, Hashmi, dan Khanum (2017) menunjukkan bahwa guru di sekolah umum lebih dapat menerima siswa dengan jenis kategori yang ringan (visual dan pendengaran) dan memiliki sikap yang agak berbeda terkait dengan siswa yang tunarungu dan tunawicara.

Salah satu penelitian terdahulu yang mendukung penelitian ini yaitu Handayani dan Rahadian (2013) yang memaparkan bahwa terdapat kelompok lain yang tidak dapat mengenyam pendidikan dasar yaitu siswa berkebutuhan khusus (ABK) dimana terdapat sekitar $70 \%$ ABK yang belum mengenyam pendidikan di sekolah, baik sekolah khusus ataupun sekolah inklusif. Berdasarkan latar belakang tersebut, penelitian ini bertujuan untuk menjabarkan (1) keberadaan, (2) model pendidikan inklusif, dan (3) jenis siswa berkebutuhan khusus (ABK) yang diterima di SD penyelenggara pendidikan inklusif kota Medan.

\section{METODE}

Penelitian ini menggunakan pendekatan kuantitatif dengan jenis penelitian deskriptif. Subjek penelitian ini yaitu 4 Sekolah Dasar Negeri (SDN) penyelenggara pendidikan inklusif di kota Medan Marelan yaitu (1) SDN No. 067261 (2) SDN No. 066429 (3) SDN No. 064007 dan (4) SDN No. 064999. Metode pengumpulan data yang digunakan dalam pelaksanaan penelitian ini adalah dengan observasi langsung, wawancara, dan dokumentasi. Analisis data dalam penelitian ini menggunakan analisis kuantitatif deskriptif dengan persentase sebagaimana disajikan pada rumus berikut.

$$
\mathrm{P}=\frac{f}{n} \times 100 \%
$$

\section{Keterangan : \\ P : Jumlah persentase deskripsi deskriptor \\ f : Jumlah subjek deskripsi \\ n : Jumlah keseluruhan subjek penelitian}

Teknik pemeriksaan keabsahan data merupakan rangkaian dari proses analisis data yaitu untuk menentukan validitas dan reliabilitas suatu data. Teknik pemeriksaan keabsahan data yang digunakan yaitu teknik triangulasi yaitu dengan membandingkan dan mengecek baik suatu informasi yang diperoleh melalui waktu dan alat yang berbeda dalam metode kualitatif.

Tabel 1 Klasifikasi Jenis Kebutuhan Khusus

\begin{tabular}{cl}
\hline Kode & \\
\hline A & Tunanetra \\
B & Tunarungu, Tunawicara \\
C & Tunagrahita Ringan $(\mathrm{IQ}=50-70)$ \\
C1 & Tunagrahita Sedang $(\mathrm{IQ}=25-50)$ \\
D & Tunadaksa Ringan \\
D1 & Tunadaksa Sedang \\
E & Tunalaras ( disruptive ), HIV, AIDS \& Narkoba \\
F & Autis, dan Sindrom Asperger \\
G & Tunaganda \\
H & Kesulitan Belajar/Lambat Belajar (antara lain: Hyperaktif, Dysgraphia/Tulis, Dyslexia/Baca, Dysphsia/Bicara, Dyscalculia/ \\
\hline
\end{tabular}




\section{HASIL}

Bagian ini membahas hasil penelitian yang dilakukan yang berkontribusi pada: (1) keberadaan siswa berkebutuhan khusus di SD yang diteliti, (2) model penempatan siswa berkebutuhan khusus, dan (3) jenis siswa berkebutuhan khusus di SD penyelenggara pendidikan inklusif. Statistik deskriptif disajikan untuk memberikan gambaran sederhana terkait dengan hasil penelitian yang dilakukan dengan kategorisasi per sekolah subjek penelitian yaitu SDN No. 067261, SDN No. 066429, SDN No. 064007 dan SDN No. 06499.

Sebagaimana disajikan pada Tabel 2, terdapat siswa berkebutuhan khusus yang berada pada setiap rombongan kelas dimana secara keseluruhan siswa dengan jenis $\mathrm{ABK} \mathrm{Cl}$ berjenis kelamin laki-laki berjumlah 14 orang dan siswa berjenis kelamin perempuan berjumlah 16 orang. Model penempatan siswa berkebutuhan khusus di SDN No. 067261 dengan model kelas reguler dengan pull out. Dapat diketahui jenis kebutuhan siswa di setiap rombongan belajar dengan jenis kebuthan khusus yang sama yaitu $\mathrm{C} 1$; tunagrahita sedang $(\mathrm{IQ}=25-50)$.

Berdasarkan data dari Tabel 3 didapatkan informasi bahwa siswa berkebutuhan khusus berada pada setiap rombongan kelas kecuali dikelas 1 karena belum dilakukan assesmen terhadap siswa baru dan di rombongan kelas 6 tidak terdapat siswa berkebutuhan khusus. Dapat diketahui jenis kebutuhan siswa di setiap rombongan belajar dengan jenis kebutuhan khusus yang sama yaitu $C$ dengan tunagrahita ringan $(\mathrm{IQ}=50-70)$. Adapun berdasarkan jenis kelamin, siswa berkebutuhan khusus kategori C di No. 064007 terdiri dari 13 siswa laki-laki dan 12 siswa perempuan dengan jumlah total 25 siswa. Model penempatan siswa berkebutuhan khusus di SDN No. 064007 menggunakan model kelas reguler dengan cluster.

Tabel 2 Data Siswa yang Memiliki Kebutuhan Khusus Pada Setiap Kelas SDN No 067261

\begin{tabular}{|c|c|c|c|c|c|c|c|c|c|c|c|c|c|}
\hline \multirow{3}{*}{ Jenis ABK } & \multicolumn{13}{|c|}{ Jumlah Siswa Berkebutuhan Khusus } \\
\hline & \multicolumn{2}{|c|}{ Kelas I } & \multicolumn{2}{|c|}{ Kelas II } & \multicolumn{2}{|c|}{ Kelas III } & \multicolumn{2}{|c|}{ Kelas IV } & \multicolumn{2}{|c|}{ Kelas V } & \multicolumn{2}{|c|}{ Kelas VI } & \multirow{2}{*}{ Jumlah } \\
\hline & $\mathbf{L}$ & $\mathbf{P}$ & $\mathbf{L}$ & $\mathbf{P}$ & $\mathbf{L}$ & $\mathbf{P}$ & $\mathbf{L}$ & $\mathbf{P}$ & $\mathbf{L}$ & $\mathbf{P}$ & $\mathbf{L}$ & $\mathbf{P}$ & \\
\hline \multicolumn{14}{|l|}{ A } \\
\hline \multicolumn{14}{|l|}{ B } \\
\hline \multicolumn{14}{|l|}{$\mathrm{C}$} \\
\hline $\mathrm{C} 1$ & 2 & 3 & 2 & 2 & 3 & 4 & 2 & 2 & 3 & 2 & 2 & 3 & 30 \\
\hline \multicolumn{14}{|l|}{$\mathrm{D}$} \\
\hline \multicolumn{14}{|l|}{ D1 } \\
\hline \multicolumn{14}{|l|}{$\mathrm{E}$} \\
\hline \multicolumn{14}{|l|}{$\mathrm{F}$} \\
\hline \multicolumn{14}{|l|}{ G } \\
\hline $\mathrm{H}$ & & & & & & & & & & & & & \\
\hline
\end{tabular}

Sumber : Data SDN No. 067261

Tabel 3 Data Siswa yang Memiliki Kebutuhan Khusus Pada Setiap Kelas SDN No. 064007

\begin{tabular}{|c|c|c|c|c|c|c|c|c|c|c|c|c|c|}
\hline \multirow{3}{*}{ Jenis ABK } & \multicolumn{13}{|c|}{ Jumlah Siswa Berkebutuhan Khusus } \\
\hline & \multicolumn{2}{|c|}{ Kelas I } & \multicolumn{2}{|c|}{ Kelas II } & \multicolumn{2}{|c|}{ Kelas III } & \multicolumn{2}{|c|}{ Kelas IV } & \multicolumn{2}{|c|}{ Kelas V } & \multicolumn{2}{|c|}{ Kelas VI } & \multirow{2}{*}{ Jumlah } \\
\hline & $\mathbf{L}$ & $\mathbf{P}$ & $\mathbf{L}$ & $\mathbf{P}$ & $\mathbf{L}$ & $\mathbf{P}$ & $\mathbf{L}$ & $\mathbf{P}$ & $\mathbf{L}$ & $\mathbf{P}$ & $\mathbf{L}$ & $\mathbf{P}$ & \\
\hline \multicolumn{14}{|l|}{$\mathrm{A}$} \\
\hline \multicolumn{14}{|l|}{$\mathrm{B}$} \\
\hline $\mathrm{C}$ & & & 1 & & 3 & 6 & 7 & 4 & 2 & 2 & & & 25 \\
\hline \multicolumn{14}{|l|}{$\mathrm{C} 1$} \\
\hline \multicolumn{14}{|l|}{$\mathrm{D}$} \\
\hline \multicolumn{14}{|l|}{ D1 } \\
\hline \multicolumn{14}{|l|}{ E } \\
\hline \multicolumn{14}{|l|}{$\mathrm{F}$} \\
\hline \multicolumn{14}{|l|}{ G } \\
\hline $\mathrm{H}$ & & & & & & & & & & & & & \\
\hline
\end{tabular}


Tabel 4 Data Siswa yang Memiliki Kebutuhan Khusus Pada Setiap Kelas SDN No. 064999

\begin{tabular}{|c|c|c|c|c|c|c|c|c|c|c|c|c|c|}
\hline \multirow{3}{*}{ Jenis ABK } & \multicolumn{13}{|c|}{ Jumlah Siswa Berkebutuhan Khusus } \\
\hline & \multicolumn{2}{|c|}{ Kelas I } & \multicolumn{2}{|c|}{ Kelas II } & \multicolumn{2}{|c|}{ Kelas III } & \multicolumn{2}{|c|}{ Kelas IV } & \multicolumn{2}{|c|}{ Kelas $\mathbf{V}$} & \multicolumn{2}{|c|}{ Kelas VI } & \multirow{2}{*}{ Jumlah } \\
\hline & $\mathbf{L}$ & $\mathbf{P}$ & $\mathbf{L}$ & $\mathbf{P}$ & $\mathbf{L}$ & $\mathbf{P}$ & $\mathbf{L}$ & $\mathbf{P}$ & $\mathbf{L}$ & $\mathbf{P}$ & $\mathbf{L}$ & $\mathbf{P}$ & \\
\hline \multicolumn{14}{|l|}{ A } \\
\hline B & & & 1 & & & & & & & & & & 1 \\
\hline $\mathrm{C}$ & & & & & 1 & & & & & & & & 1 \\
\hline $\mathrm{C} 1$ & 1 & 1 & & & & & & & & & & & 2 \\
\hline \multicolumn{14}{|l|}{ D } \\
\hline \multicolumn{14}{|l|}{ D1 } \\
\hline \multicolumn{14}{|l|}{ E } \\
\hline \multicolumn{14}{|l|}{$\mathrm{F}$} \\
\hline \multicolumn{14}{|l|}{ G } \\
\hline $\mathrm{H}$ & & & 3 & & 4 & 1 & 3 & 1 & 2 & 1 & 1 & 2 & 18 \\
\hline
\end{tabular}

Sumber : Data SDN No. 064999

Tabel 5 Data Siswa yang Memiliki Kebutuhan Khusus Pada Setiap Kelas SDN No. 064999

\begin{tabular}{|c|c|c|c|c|c|c|c|c|c|c|c|c|c|}
\hline \multirow{3}{*}{ Jenis ABK } & \multicolumn{13}{|c|}{ Jumlah Siswa Berkebutuhan Khusus } \\
\hline & \multicolumn{2}{|c|}{ Kelas I } & \multicolumn{2}{|c|}{ Kelas II } & \multicolumn{2}{|c|}{ Kelas III } & \multicolumn{2}{|c|}{ Kelas IV } & \multicolumn{2}{|c|}{ Kelas V } & \multicolumn{2}{|c|}{ Kelas VI } & \multirow{2}{*}{ Jumlah } \\
\hline & $\mathbf{L}$ & $\mathbf{P}$ & $\mathbf{L}$ & $\mathbf{P}$ & $\mathbf{L}$ & $\mathbf{P}$ & $\mathbf{L}$ & $\mathbf{P}$ & $\mathbf{L}$ & $\mathbf{P}$ & $\mathbf{L}$ & $\mathbf{P}$ & \\
\hline \multicolumn{14}{|l|}{ A } \\
\hline \multicolumn{14}{|l|}{ B } \\
\hline $\mathrm{C}$ & & & 3 & 4 & 1 & 3 & 4 & 2 & 4 & 4 & 5 & & 30 \\
\hline \multicolumn{14}{|l|}{$\mathrm{C} 1$} \\
\hline \multicolumn{14}{|l|}{$\mathrm{D}$} \\
\hline \multicolumn{14}{|l|}{ D1 } \\
\hline \multicolumn{14}{|l|}{ E } \\
\hline \multicolumn{14}{|l|}{$\mathrm{F}$} \\
\hline \multicolumn{14}{|l|}{ G } \\
\hline $\mathrm{H}$ & & & & & & & & & & & & & \\
\hline
\end{tabular}

Sumber : Data SDN No. 064999

Tabel 4 menunjukkan bahwa siswa berkebutuhan khusus berada pada setiap rombongan kelas. Namun penempatan siswa berkebutuhan khusus di tempatkan di kelas khusus penuh untuk siswa berkebutuhan khusus, jika setelah diasesmen dapat kembali ditempatkan di kelas reguler bersama siswa reguler. Adapun berdasarkan jenis kelamin, siswa berkebutuhan khusus kategori C di No. 064999 terdiri dari 16 siswa laki-laki dan 6 siswa perempuan dengan jumlah total 22 siswa. Dapat diketahui jenis kebutuhan khusus siswa di setiap rombongan belajar dengan jenis kebuthan khusus yang berbedabeda yaitu; tunarungu 1 siswa, tunagrahita ringan 1 siswa, tungarahita sedang 2 siswa dan siswa yang kesulitan belajar (hyperaktif, kesulitan baca, tulis, berhitung dan berbicara) 18 orang.

Berdasarkan data dari Tabel 5 diketahui bahwa siswa berkebutuhan khusus berada pada setiap rombongan kelas kecuali dikelas 1 karena belum dilakukan assesmen terhadap siswa baru. Adapun berdasarkan jenis kelamin, siswa berkebutuhan khusus kategori C di No. 064999 terdiri dari 17 siswa laki-laki dan 13 siswa perempuan dengan jumlah total 30 siswa. Penempatan siswa berkebutuhan khusus di tempatkan di kelas reguler dengan cluster. Dapat diketahui jenis kebutuhan siswa di setiap rombongan belajar dengan jenis kebuthan khusus yang sama yaitu $C$ yaitu tunagrahita ringan $(\mathrm{IQ}=50-70)$.

Model penempatan siswa berkebutuhan khusus di SDN No. 067261 yaitu model kelas reguler dengan pull out. Model penempatan siswa berkebutuhan khusus di SDN No. 064007 yaitu model kelas reguler dengan cluster. Sedangkan SDN 064999 model kelas khusus penuh. SDN 066429 penerapan model kelas yang sama dengan SDN 067261 yaitu kelas reguler dengan cluster. Berdasarkan data 
tersebut, model kelas penyelenggara inklusif di SDN Medan Marelan 50\% sekolah memilih dengan model kelas reguler dengan cluster. Hasil penelitian lebih menekankan pada kelas reguler dengan cluster yaitu siswa berkebutuhan khusus belajar bersama dengan siswa non berkebutuhan khusus di kelas reguler dalam kelompok khusus.

Berdasarkan data dari Tabel 6 daftar keberadaan dan jenis siswa berkebutuhan khusus di SD penyelenggara pendidikan inklusif menunjukkan hamper seluruh siswa berkebutuhan khusus berada pada setiap rombongan kelas baik mulai kelas I atau kelas II hingga kelas VI. Jenis kebutuhan khusus siswa terdapat 4 jenis kebutuhan khusus yaitu sebagian besar (52\%) siswa merupakan kategori tunagrahita ringan, sebanyak $30 \%$ siswa termasuk kategori tunagrahita sedang, sebanyak $17 \%$ siswa termasuk kategori kesulitan belajar, dan hanya 1 siswa yang termasuk dalam kategori tunarungu.

\section{PEMBAHASAN}

Penelitian ini mengkaji keberadaan, model, dan jenis siswa berkebutuhan khusus di empat SDN yang ada di Medan. Hasil penelitian menunjukkan bahwa sebagian besar $(75 \%)$ siswa berada pada di setiap rombongan belajar/kelas reguler dan sebanyak $25 \%$ siswa berada pada di rombongan belajar/kelas khusus inklusif sekolah reguler. Hal tersebut menunjukkan bahwa penerimaan siswa berkebutuhan khusus sudah didukung oleh instansi terkait. Terlebih lagi hasil tersebut menunjang adanya kesetaraan untuk semua dengan meminimalisir ketidakinsklusifan di semua aspek kehiudupan yang secara umum mendukung model sosial yang ada (Fernández, 2017). Lebih lanjut, dengan adanya pencampuran tersebut, diusahakan agar siswa normal dapat menerima dan memahami siswa yang bebeda dalam pembelajaran di kelas (Hwang dan Evans, 2011).

Terkait dengan model penempatan siswa, hasil penelitian menunjukan sebanyak dua sekolah menempatkan siswa pada kelas reguler dengan cluster, satu sekolah menggunakan kelas reguler dengan pull out, dan satu sekolah menggunakan kelas khusus penuh. Hal ini sejalan dengan pendapat Ashman (dalam Elisa, 2013) bahwa sekolah dapat menjalankan model pendidikan siswa berkebutuhan khusus di sekolah inklusif yaitu (1) kelas reguler (inklusif penuh), (2) kelas reguler dengan cluster, (3) kelas reguler dengan pull out, (4) kelas reguler dengan cluster dan pull out, (4) kelas khusus dengan berbagai pengintegrasian, dan (5) kelas khusus penuh. Terkait dengan hasil penelitian tersebut, diperlukan pengelolaan yang cermat mulai dari fasilitas serta guru yang memadai bila menggunakan model kelas reguler dengan model pull out (Mardini, 2016). Lebih lanjut, studi menunjukkan bahwa minat belajar anak berkebutuhan khusus lebih meningkat dalam model ini (Mardini, 2016 dan Fitrianah, 2018).

Terkait dengan siswa dan jenis kebutuhan khususnya ditemukan data sebanyak $52 \%$ siswa $(\mathrm{ABK})$ termasuk dalam kategori tunagrahita ringan, sebagian kecil (30\%) tunagrahita sedang, sebanyak $17 \%$ mengalami kesulitan belajar, dan hanya $1 \%$ siswa yang berada di kategori tunarungu. Hasil tersebut sejalan dengan pendapat Khan, Hashmi, dan Khanum (2017) yang mengindikasikan bahwa penerimaan lebih mudah dilakukan bila jenis kebutuhan khusus siswa tersmasuk kategori ringan dan lebih focus pada kesulitan belajar. Hal ini sebagimana gambaran umum bahwa penyelenggara pendidikan inklusif, keberadaan dan penempatan siswa yang memiliki kebutuhan khusus, potensi khusus, minat, bakat dan kecerdasan khusus sangat diperhatikan pada implementasi pendidikan inklusif. Lebih lanjut, hasil penelitian Sunanto (2009) menunjukkan bahwa jumlah ABK di SD inklusif bervariasi dari 1 sampai 4 anak dengan jenis ABK dengan learning disability (LD) lebih banyak ditemukan di samping anak autis dan tunagrahita.

Tabel 6 Daftar Keberadaan dan Jenis ABK di SD

\begin{tabular}{|c|c|c|c|c|c|c|c|c|}
\hline \multirow{2}{*}{ No } & \multirow[b]{2}{*}{ Jenis ABK } & \multirow[b]{2}{*}{ Kelas } & \multicolumn{4}{|c|}{ Jumlah ABK } & \multirow[b]{2}{*}{ Jumlah } & \multirow[b]{2}{*}{ Persentase } \\
\hline & & & $\begin{array}{c}\text { SDN } \\
067261\end{array}$ & $\begin{array}{c}\text { SDN } \\
064007\end{array}$ & $\begin{array}{c}\text { SDN } \\
064999\end{array}$ & $\begin{array}{c}\text { SDN } \\
066429\end{array}$ & & \\
\hline 1 & $\mathrm{C} 1=$ Tunagrahita Sedang & I s/d VI & 30 & & 2 & & 32 & $30 \%$ \\
\hline 2 & $\mathrm{C}=$ Tunagrahita Ringan & II s/d V & & 25 & 1 & 30 & 56 & $52 \%$ \\
\hline 3 & $\mathrm{~B}=$ Tunarungu & II & & & 1 & & 1 & $1 \%$ \\
\hline \multirow[t]{2}{*}{4} & $\mathrm{H}=$ Kesulitan Belajar & II s/d VI & & & 18 & & 18 & $17 \%$ \\
\hline & & & & & & & 107 & $100 \%$ \\
\hline
\end{tabular}




\section{SIMPULAN DAN SARAN}

\section{Simpulan}

Berdasarkan hasil analisis dan pembahasan dalam penelitian ini, dapat ditarik simpulan yaitu sebagian besar (75\%) siswa berada pada di setiap rombongan belajar/kelas reguler dan sebanyak $25 \%$ siswa berada pada di rombongan belajar/ kelas khusus inklusif sekolah reguler (kelas khusus penuh). Terkait dengan model pembelajaran inklusif, dua sekolah menempatkan siswa pada kelas reguler dengan cluster, satu sekolah menggunakan kelas reguler dengan pull out, dan satu sekolah menggunakan kelas khusus penuh. Jenis kebutuhan khusus siswa (ABK) sebagian besar (52\%) tunagrahita ringan, sebagian kecil (30\%) tunagrahita sedang, sebagian kecil (17\%) kesulitan belajar, dan sebagian kecil (1\%) tunarungu.

\section{Saran}

Berdasarkan hasil penelitian ini dapat ditarik beberapa saran yang dibutuhkan untuk peningkatan kualitas penyelenggaraan pendidikan inklusif bagi siswa berkebutuhan khusus di Medan. Secara umum saran diberikan kepada penyelenggaran baik pemerintah dan sekolah untuk menempatkan siswa di setiap kelas reguler dan menerima siswa dalam penempatan di sekolah umum. Kepada pemerintah, diharapkan untuk terus dapat mendukung penyelenggara pendidikan inklusif agar sekolah penyelenggara pendidikan inklusif dapat tetap menyelenggrakan pendidikan inklusif dengan sesuai pedoman dan idealnya pendidikan inklusif serta dapat bertambah sekolah penyelenggara pendidikan inklusif khususnya di Sumatera Utara dan kota Medan. Adapun kepada sekolah diharapkan untuk selalu mengevaluasi dan merevisi implementasi pendidikan inklusif agar dapat menjadi sekolah contoh penyelenggara pendidikan inklusif serta sekolah yang belum menyelenggarakan dapat dengan segera menyelenggarakan pendidikan yang sesuai dengan model yang dibutuhkan.

\section{DAFTAR RUJUKAN}

Abbas, F., \& Naz, T. (2016). Footstep towards Inclusive Education. Journal of Education and Practice, 5.

Atika, T. (2018). Efektivitas Serta Dukungan Keluarga Terhadap Terapi Anak Autis di
Kaizen Nirel Centre Yayasan Pembinaan Anak Berkebutuhan Khusus (ABK) Kecamatan Medan Tuntungan Simalingkar Perumnas A Medan. Medan: Universitas Sumatera Utara

Devy, P. I. 2017. Impelementasi Kebijakan Pendidikan Inklusif Untuk ABK di Surabaya. Jurnal Dimensi Pendidikan dan Pembelajaran. (Online), Jilid 5, No. 1

Elisa, S., \& Wrastari, A. T. (2013). Sikap guru terhadap pendidikan inklusi ditinjau dari faktor pembentuk sikap. Jurnal Psikologi Perkembangan dan Pendidikan, 2(01), 1-10.

Fernández, M. T. (2017). Attitudes toward Inclusive Education and Practical Consequences in Final Year Students of Education Degrees. Procedia - Social and Behavioral Sciences, 237, 1184-1188. https://doi.org/10.1016/j. sbspro.2017.02.187

Fitrianah, N. (2018). Meningkatkan Minat Belajar Anak Inklusi Melalui Model Pull Out di MI Nurul Huda Kalanganyar Sedati. Universitas Muhammadiyah Sidoarjo.

Handayani, T., \& Rahadian, A. S. (2013). Peraturan perundangan dan implementasi pendidikan inklusif. Masyarakat Indonesia, 39(1), 27-48.

Hwang, Y.-S., \& Evans, D. (2011). Attitudes towards inclusion: Gaps between belief and practice. International Journal of Special Education, 26(1), 136-146.

Ilahi, M. T. (2013). Pendidikan Inklusif: Konsep dan Aplikasi. Yogyakarta: Ar-Ruzz Media.

Khan, I. K., Hashmi, S. H., \& Khanum, N. (2017). Inclusive Education in Government Primary Schools: Teacher Perceptions. Journal of Education and Educational Development, 4(1), 32. https://doi.org/10.22555/joeed.v4i1.1331

Mardini, S. (2016). Meningkatkan Minat Belajar Anak Berkebutuhan Khusus di Kelas Reguler Melalui Model Pull Out Di SDN Giwangan Yogyakarta. JURNAL JPSD (Jurnal Pendidikan Sekolah Dasar), 2(1), 25. https:// doi.org/10.26555/jpsd.v2i1.a4952

Peraturan Menteri Pendidikan Nasional (Permendiknas) Republik Indonesia Nomor 70 Tahun 2009 tentang Pendidikan Inklusif bagi Siswa yang Memiliki Kelainan dan Memiliki Potensi Kecerdasan dan/atau Bakat Istimewa. (2009). Jakarta: Sekretariat Negara.

Undang-Undang Republik Indonesia Nomor 20 Tahun 2013 tentang Sistem Pendidikan 
24 Sekolah Dasar: Kajian Teori dan Praktik Pendidikan, Tahun 28 Nomor 1, Mei 2019, hlm 17-24

Nasional. (2013). Jakarta: Sekretariat Negara.

Prastiono. (2013). Implementasi Kebijakan

Pendidikan Inklusif. Jurnal Administrasi Publik. (Online), Jilid 11, No. 1.

Priyadarshini, S. S., \& Thangarajathi, S. (2017). Effect of Selected Variables on Regular School Teachers Attitude towards Inclusive Education. Journal on Educational Psychology, 10(3), 28-38.

Sunanto, J. (2009). Profil Implementasi Pendidikan Inklusif Sekolah Dasar di Kota Bandung. Bandung: Universitas Pendidikan Indonesia. 